\title{
A Study on Strategic Management of Higher Vocational Colleges
}

\section{Yawei Chen}

Changzhou Vocational Institute of Mechatronic Technology,Changzhou, Jiangsu,China,213164

\author{
Key words: Higher Vocational Colleges,Strategic Management,Several Problems
}

\begin{abstract}
The paper discusses the important significance that the higher vocational colleges carry out the strategic management, focuses on the prominent problems when these colleges plan, make, implement, supervise and assess these strategies, analyzes major difficulties of carrying out the comprehensive strategic management, expects to provide some theoretical references for "the 13th five-year plan" of colleges.
\end{abstract}

\section{Introduction}

Strategic management of higher vocational colleges is the colleges' overall, long-term development direction, targets, tasks as well as the decisions and management of resource allocation in a long future time. Its main contents include the formulation, implementation, supervision, assessment and feedback of the strategic planning. In 2002, “work assessment of higher vocational colleges' talent cultivation" index system issued by Ministry of Education clearly stated that school strategic planning would be included into the examination items. This is the important basis for higher vocational colleges to carry out strategic management. In 2006 and 2010, Ministry of Education successively started "construction engineering of one hundred of demonstration higher vocational colleges" and "construction project of backbone colleges". These projects are the landmark of higher vocational colleges' strategic management. With the implementation of these two construction projects, higher vocational colleges have fiercer and fiercer competitions. It is the demand of a new age for these colleges to turn their short-term development goal into medium and long-term one. It is necessary for them to carry out strategic management.

\section{Problems and Cause Analysis of Higher Vocational Colleges' Strategic Management}

Medium and long-term planning is the programmatic document for higher vocational colleges to achieve strategic management. These colleges are required to focus on medium and long-term planning and do each job well while carrying out strategic management. Since most higher vocational colleges have a short history and lack strategic management experience, they have various problems in making and implementing strategic management. These problems shall be studied and solved. It shall be greatly significant to help the higher vocational colleges' healthy development.

Formulaic Analysis of Internal and External Environment,Poor Public Participation.Medium and long-term planning is based on the successful experience accumulation of preliminary work and a comprehensive analysis of colleges' internal and external environment in a future time. Before the strategic planning is made, preliminary work has to be summarized, the internal and external environment faced by colleges at present as well as in a rather long future time shall be analyzed, investigated and studied further to find out the successful experience and problems. These experience and problems shall be valued when the planning is made. Currently, many colleges have formulaic internal and external environment analysis and opinion survey, poor teaching staff participation etc in the earlier planning period. These analyses and opinions surveys lack substantial contents[1].

Improper and infeasible target.The target of strategic planning is the director of colleges' future efforts and has the important guidance significance for colleges' development. Some colleges have the improper targets, higher expectation, poor feasibility. It leads to various difficulties in the implementation of the planning. These colleges fail to understand the planning significance well, 
lack the enough study on core and key problems of the planning, have little rational analysis and feasibility[2].

Poor supervision and executive force in the implementation process.Medium and long-term planning is usually carried out by year. The planning target, task and measures must be included into colleges' yearly work plan and be supervised in the whole process. The current problem is the disconnection of planning implementation and colleges' yearly work plan, the lack of process supervision. Many factors lead to this situation, such as no specific target and task of planning, disconnection of planning and yearly work plan, unclear responsibility, poor supervision and executive force.

Lack of assessment and disconnection to performance.Since no complete supervision system is available in the planning implementation process, the planning implementation fails to be connected with the yearly assessment and effective performance evaluation can not be carried out. Poor supervision measures of planing implementation make its seriousness worse.

Non-standard variation procedure and serious randomness. Medium and long-term planning is the guidance document of colleges' sustainable development. It needs to keep pace with the times with the change of internal and external environment. Some contents of planning must be adjusted properly. The common problem is that there lacks the standard feasibility analysis in the planning change process, strict change procedure. It damages the seriousness of planning badly.

\section{Some Problems Need to be Solved for Making and Implementing Strategic Planning}

Based on the analysis above, the following problems must be solved to carry out the comprehensive strategic management:

Understand the significance of strategic planning to higher vocational colleges' development.Strategic planning is good for the school-running characteristics cultivation of higher vocational colleges

School-running characteristics are the important symbol of modern higher vocational colleges' school-running level. It is the long stable development way and the social recognized, unique and excellent school-running characteristics during the colleges' development course. The formation of school-running characteristics needs colleges' long-term cultivation and accumulation. Strategic planning focuses on the long-term development of colleges and provides colleges with the good opportunity and ideas to develop school-running characteristics.

Strategic planning contributes to improvement of higher vocational colleges' management system.Strategic management emphasizes the definition, normalization and feasibility of strategic target. This way it can avoid the passivity, blindness and randomness of colleges' management work. Since strategic implementation is closely connected to daily management, colleges can connect the management system with strategic target based on strategic management. It not only standardizes management work but also fully encourages the public to take part in strategic management positively, enhances the rally power and guarantees the implementation of strategic target.

Solve core problems of higher vocational colleges' strategic management.First, the core problem is scientificity, normalization and mass in terms of strategic planning. Only when problems are located, development direction is determined and development target is clear can targeted measures be taken. Finally key problems influencing the colleges' development shall be solved to lay a good foundation for colleges' development.

Second, the core problem is appropriateness in terms of planning target and location. The problem of the strategic planning needs to be found out and the reasonable target needs to be determined when strategic planning target is determined during the analysis change and exploration. This way it can be the guidance document of colleges' development.

Third, the core problem is the determination of strategic key points in terms of the whole planning contents. The core competitiveness of higher vocational colleges is the specialty competitive capacity of higher vocational colleges essentially. It reflects the main index of colleges' school-running level. Therefore, the core of strategic planning shall focus on this key point, serve this key point and create conditions for the realization of the key point[3]. 
Fourth, the core problem is the implementation of the supervision measures in terms of executive process. Currently, many colleges fail to realize this problem based on strategic management and lack the clear target and task. The relevant department and staff have no clear responsibility. No effective supervision and assessment is available, work arbitrariness is serious, planning making is disconnected with planning implementation and the executive force is poor during the implementation process.

\section{Conclusions}

In conclusion, strategic management is a large and complex system engineering. It involves the planning formation, implementation, supervision, assessment and feedback. These items are dispensable. Strategic management involves various factors of higher vocational colleges and needs the all teaching staff participation. Each job needs to be well planned. Only in this way can it play a leading role in higher vocational colleges' development and be the internal impetus of higher vocational colleges’ development.

\section{References}

[1] Wang Hao Reflection on Strategic Management Theory Development, modern business, 2009(2),54-55,2009

[2] Hu Shenghao, From Strategy to Implementation — the way of strategy formation, China economic publishing house, 22-23,2012

[3] Wang Ruomei Several Problems on Colleges' Strategic Management Research, educational criticism 2012(2), 27-29,2012 